\title{
Proximate Compositions, Physicochemical and Sensory Properties of Gari Fortified with Soybean, Melon Seed and Moringa Seed Flours
}

\author{
Alozie Yetunde Ezinwanyi, Ekerette Nkereuwem Ndaeyo \\ Department of Home Economics, Nutrition and Dietetics, University of Uyo, Uyo, Nigeria \\ Email address: \\ nekerette@yahoo.com (E. N. Ndaeyo) \\ To cite this article: \\ Alozie Yetunde Ezinwanyi, Ekerette Nkereuwem Ndaeyo. Proximate Compositions, Physicochemical and Sensory Properties of Gari \\ Fortified with Soybean, Melon Seed and Moringa Seed Flours. International Journal of Nutrition and Food Sciences. \\ Vol. 6, No. 2, 2017, pp. 105-110. doi: 10.11648/j.ijnfs.20170602.17
}

Received: October 29, 2016; Accepted: December 14, 2016; Published: March 4, 2017

\begin{abstract}
Gari was fortified with soybean, melon seed and moringa seed flours at 5\% substitution level to produce Soy gari, Melon seed gari and Moringa seed gari respectively. A control sample, $100 \%$ cassava gari was also produced. Samples were analyzed for proximate compositions, physicochemical properties and sensory characteristics using standard procedures. Results revealed that, fortification significantly decreased moisture $(9.12 \pm 0.017 \%$ in Control to $8.14 \pm 0.04 \%$ in Soy gari) and fibre $(2.73 \pm 0.04 \%$ in Control to $2.11 \pm 0.02 \%$ in Melon seed gari) in all samples except in Moringa seed gari. Protein ( $1.52 \pm 0.05 \%$ in Control to $7.22 \pm 0.04 \%$ in Soy gari), fat (6.34 $\pm 0.29 \%$ in Control to $10.74 \pm 0.19 \%$ in Melon seed gari) and ash ( $1.55 \pm 0.03 \%$ in Control to $2.47 \pm 0.61 \%$ in Melon seed gari) contents were increased, while carbohydrate contents were decreased $(78.74 \pm 0.242 \%$ in Control to $71.02 \pm 0.512 \%$ in Soy gari), in all samples. For pasting properties, Moringa seed gari performed best in peak viscosity (2374.50 RVU), trough (1862.50 RVU) but poorly in breakdown viscosity (512.00 RVU); while the Control scored best in final viscosity (3018.50 RVU). Swelling index ranged from $2.43 \pm 0.05$ in Soy gari to $4.82 \pm 0.02 \%$ in Control. Water holding capacity ranged from $19.22 \pm 0.03 \%$ in Soy gari to $24.34 \pm 0.05$ in the Control. Control sample performed best in all sensory properties except in overall acceptability, where Melon seed gari scored the best. Moringa seed gari scored significantly lower than others in colour, taste, and acceptability but had similar rating in aroma to Soy gari. Gari fortified with soy beans, melon seed and moringa seed flours are of improved nutritive values, physicochemical and sensory properties than ordinary gari. Fortification of this product can thus present a viable and sustainable means of tackling nutrient deficiencies, particularly protein energy malnutrition in populations.
\end{abstract}

Keywords: Gari, Fortification, Proximate Compositions, Functional Properties, Pasting Properties, Sensory Properties

\section{Introduction}

Gari is a granular food product processed from peeled, grated, fermented, sieved and toasted cassava tuber (Manihot esculenta). It is the most commonly consumed cassava product across most geo-political zones in Nigeria [1] and constitutes a common daily menu item consumed by greater proportion of the population [2-3]. Gari can be reconstituted with hot water to form a stiff paste, usually eaten with various vegetable soups as accompaniment or with cold water to obtain a free flowing mixture usually taken with added salt, sugar, groundnut, fish, etc.

The problem with consistent consumption of gari stems from its poor nutritional value common with all cassava products. Gari is known for its high caloric value, low protein, fat and micronutrients contents. Low protein gari based diets can predispose consumers to protein-energy malnutrition with compromised renal functions [4]. Moreover, protein-energy malnutrition and micronutrient deficiencies constitute the most dreaded nutritional problems faced in developing countries [5].

Food fortification is a viable strategy to improving nutritional quality of foods and consequently enhance adequate nutritional intake among people. Enrichment of gari with protein-rich plant foods (soy beans, groundnut, seasame seed, melon seed etc) usually result in gari product with improved nutrient quality and acceptable sensory properties [6-8]. Both 
soy bean and melon seeds are rich sources of protein, essential amino and fatty acids, minerals and vitamins [9-10]. It has been stated that, due to the protein and amino acids contents in soy bean, soy foods can replace animal protein foods without requiring major adjustments in the diet [10].

Moringa oleifera is a nutritious plant with potential uses for all leaves, seeds and roots. The seed is regarded as the most valued part of the plant; and can be eaten raw or toasted like nuts [11]. Moringa oleifera seeds are good sources of minerals, indicated by high ash, lipids, crude fibre and protein contents [11]. Substituting cassava flour with Moringa oleifera seed flour in gari processing can present as a promising strategy for improving the nutritional quality of gari.

There is need to explore the potentials of some other foods as enrichment materials in gari production and to compare individual contributions of different enrichment materials to nutrients intakes from gari. This study was carried out to investigate nutrient compositions, physicochemical and sensory properties of gari enriched with soy bean, melon seed and moringa oleifera seed.

\section{Materials and Methods}

\subsection{Samples Collection}

Freshly harvested cassava roots (Manihot esculenta) were obtained from peasant farmers in Okeagbe Akoko, while Soy beans (Glycine max), melon seeds (Citrulis vulgaris) and Moringa Oleifera seeds were purchased from Oba market in Akure, all in Ondo State, Nigeria.

\subsection{Sample Preparation}

The soybean seeds were cleaned, sorted and steam heated for $30-45$ minutes at $100^{\circ} \mathrm{C}$ and allowed to cool. It was then de-hulled by rubbing between palms to remove the seed coat. The de-hulled seeds were air dried at oven temperature of 70 $80^{\circ} \mathrm{C}$ until they were completely dried and then dry milled into powder using magnetic Blender (SHB- 515 model made by Sorex Company Limited) to obtain the soy-flour. Melon seeds and Moringa seeds were sorted separately, cleaned and toasted in a steel pan at temperature of $80-90^{\circ} \mathrm{C}$. The toasted seeds were cooled and milled to obtain melon seed and Moringa seed flours respectively.

\subsection{Production of Fortified Gari}

Traditional processing method of gari production previously described was adopted [12]. Processed soybean, melon seed and Moringa seed flours were added to separate portions of cassava mesh after sieving, prior to roasting to substitute for 5\% cassava flour. Altogether, there were four (4) treatment groups: Control (100\% cassava gari), Soy gari, Melon seed gari and Moringa seed gari.

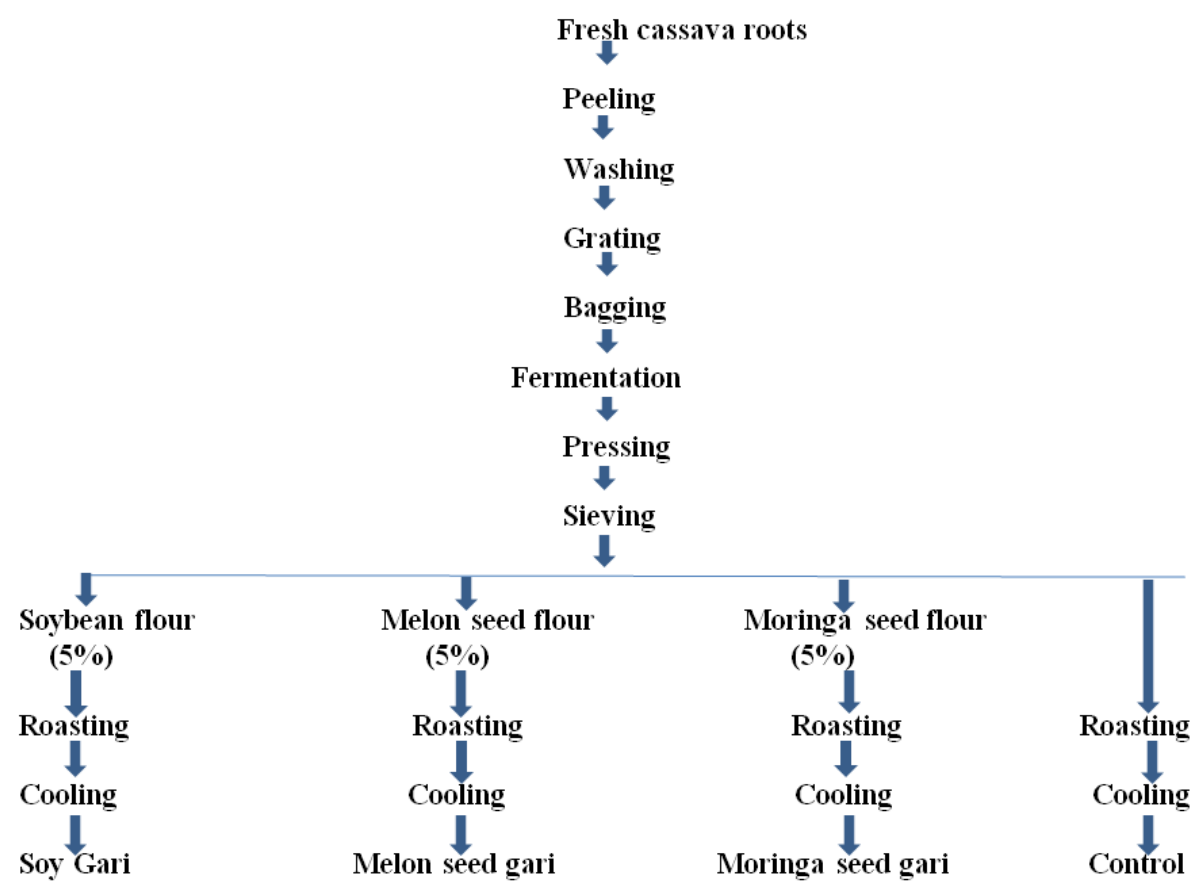

Figure 1. Process Flow Diagram for Production of Fortified Gari Products.

\subsection{Chemical Analyses}

Proximate compositions were determined according to the laid down procedures of the Association of Official Analytical Chemists [13]. Carbohydrate content was determined by difference. Titratable acidity (TTA) and $\mathrm{pH}$, water holding capacity, swelling index, and hydrogen cyanide ( $\mathrm{HCN})$ were determined according to previously described methods [13-16].

The pasting properties of the samples were assessed in a Rapid Visco Analyzer Units- RVU (model RVA 3D+, Newport Scientific Australia). The sample was turned into slurry by mixing $3 \mathrm{~g}$ with $25 \mathrm{~mL}$ of water inside the RVA can 
and inserted into the tower, which was then lowered into the system. The slurry was heated from 50 to $95^{\circ} \mathrm{C}$ and cooled back to $50^{\circ} \mathrm{C}$ within 12 minutes, rotating the can at a speed of $160 \mathrm{r} / \mathrm{min}$ with continuous stirring of the content with a plastic paddle. Parameters estimated were peak, trough, breakdown, final, setback viscosities, peak time and pasting temperature.

\subsection{Sensory Evaluation}

Samples were reconstituted with cold water for drinking and given to twenty trained panelists familiar with the product to evaluate sensory properties using a five (5) points measurement scale to assess colour, taste, aroma and general acceptability. One (1) was rated 'like most' while five (5) was rated 'dislike most'.

\subsection{Statistical Analysis}

Data were reported as means of replicate analyses. One way analysis of variance (ANOVA) was used to determine significant differences $(\mathrm{p}<0.05)$ in attributes among samples. Differences between means obtained from the ANOVA were ascertained using Duncan's Multiple Range Tests.

\section{Results}

\subsection{Proximate Compositions}

There were significant differences in proximate compositions of gari samples. Moisture contents in samples ranged from $8.14 \pm 0.040 \%$ in Soy gari to $11.96 \pm 0.026 \%$ in Moringa seed gari. The control sample had the least protein and fat contents $(1.52 \pm 0.055 \%$ and $6.34 \pm 0.299 \%)$ while Soy gari $(7.22 \pm 0.045 \%)$ and Melon seed gari (10.74 $\pm 0.191 \%)$ had the highest protein and fat values respectively. Melon seed gari had the lowest fibre content $(2.11 \pm 0.021 \%)$, while Moringa seed gari had the highest $(3.04 \pm 0.079)$. Control sample had the least ash content, whereas, the highest value $(2.47 \pm 0.612 \%)$ was reported for Melon seed gari.

Table 1. Proximate Compositions of Fortified Gari Samples.

\begin{tabular}{|c|c|c|c|c|}
\hline \multirow{2}{*}{ Proximate Compositions } & \multicolumn{4}{|l|}{ Samples } \\
\hline & Control & Soy Gari & Melon Seed Gari & Moringa Seed Gari \\
\hline Moisture (\%) & $9.12^{c} \pm 0.017$ & $8.14^{\mathrm{e}} \pm 0.040$ & $8.28^{\mathrm{d}} \pm 0.030$ & $11.96^{\mathrm{a}} \pm 0.026$ \\
\hline Protein $(\%)$ & $1.52^{\mathrm{e}} \pm 0.055$ & $7.22^{\mathrm{a}} \pm 0.045$ & $4.16^{\mathrm{b}} \pm 0.040$ & $3.54^{\mathrm{c}} \pm 0.118$ \\
\hline Fat $(\%)$ & $6.34^{\mathrm{d}} \pm 0.299$ & $8.81^{\mathrm{b}} \pm 0.364$ & $10.74^{\mathrm{a}} \pm 0.191$ & $7.61^{c} \pm 0.332$ \\
\hline Fibre $(\%)$ & $2.73^{c} \pm 0.042$ & $2.46^{\mathrm{d}} \pm 0.038$ & $2.11^{\mathrm{e}} \pm 0.021$ & $3.04^{\mathrm{a}} \pm 0.079$ \\
\hline Ash $(\%)$ & $1.55^{\mathrm{c}} \pm 0.030$ & $2.25^{\mathrm{ab}} \pm 0.021$ & $2.47^{\mathrm{a}} \pm 0.612$ & $1.76^{\mathrm{bc}} \pm 0.032$ \\
\hline Carbohydrate (\%) & $78.74^{\mathrm{a}} \pm 0.242$ & $71.02^{\mathrm{d}} \pm 0.512$ & $72.23^{\mathrm{c}} \pm 0.499$ & $73.79^{c} \pm 0.285$ \\
\hline
\end{tabular}

Mean \pm SD of triplicates. Values with the same superscript along each row are not significantly different

\subsection{Pasting and Functional Properties}

Significant differences were observed for most pasting properties of samples except in pasting temperature where all samples scored comparatively. Moringa seed gari had the highest values for peak viscosity (2374.50 RVU), trough (1862.50 RVU) and breakdown viscosity (512.00 RVU) while Control scored highest values for final viscosity (3018.50 RVU) and setback viscosity (1229.00
RVU). Soy gari scored the least for peak viscosity (1016.50 RVU), trough (926.00 RVU), final viscosity (1666.00 RVU) and setback viscosity (740.00 RVU). The lowest value (84.50 RV) for breakdown viscosity was recorded for Melon seed gari. Swelling index ranged from $2.43 \pm 0.05 \%$ in Soy gari to $4.82 \pm 0.02 \%$ in Control. Water holding capacity ranged from $19.22 \pm 0.03 \%$ in Soy gari to $24.34 \pm 0.05$ in the Control.

Table 2. Pasting and Functional Properties of Fortified Gari Samples.

\begin{tabular}{|c|c|c|c|c|}
\hline \multirow{2}{*}{ Pasting Characteristics } & \multicolumn{4}{|l|}{ Samples } \\
\hline & Control & Soy Gari & Melon Seed Gari & Moringa Seed Gari \\
\hline Peak Viscosity (RVU) & $1902.50^{\mathrm{b}}$ & $1016.50^{\mathrm{d}}$ & $1595.00^{\mathrm{c}}$ & $2374.50^{\mathrm{a}}$ \\
\hline Trough (RVU) & $1789.50^{\mathrm{ab}}$ & $926.00^{\mathrm{c}}$ & $1510.50^{\mathrm{b}}$ & $1862.50^{\mathrm{a}}$ \\
\hline Breakdown Viscosity (RVU) & $113.00^{\mathrm{b}}$ & $90.50^{\mathrm{b}}$ & $84.50^{\mathrm{b}}$ & $512.00^{\mathrm{a}}$ \\
\hline Final Viscosity (RVU) & $3018.50^{\mathrm{a}}$ & $1666.00^{\mathrm{c}}$ & $2585.50^{\mathrm{b}}$ & $2818.00^{\mathrm{ab}}$ \\
\hline Setback Viscosity (RVU) & $1229.00^{\mathrm{ab}}$ & $740.00^{\mathrm{c}}$ & $1075.00^{\mathrm{ab}}$ & $955.50^{\mathrm{bc}}$ \\
\hline Peak Time (Min) & $6.10^{\mathrm{bc}}$ & $6.60^{\mathrm{ab}}$ & $6.06^{\mathrm{bc}}$ & $5.76^{\mathrm{c}}$ \\
\hline Swelling Index $(\%)$ & $4.82 \pm 0.02^{\mathrm{a}}$ & $2.43 \pm 0.05^{\mathrm{d}}$ & $2.22 \pm 0.04^{\mathrm{d}}$ & $2.97 \pm 0.05^{\mathrm{c}}$ \\
\hline Water Holding Capacity $(\%)$ & $24.34 \pm 0.05^{\mathrm{a}}$ & $19.22 \pm 0.03^{\mathrm{c}}$ & $22.80 \pm 0.05^{\mathrm{b}}$ & $23.05 \pm 0.05^{\mathrm{a}}$ \\
\hline
\end{tabular}

$\mathrm{Mean} \pm \mathrm{SD}$ of triplicates. Values with the same superscript along each row are not significantly different.

\subsection{Changes in Hydrogen Cyanide, $\mathrm{pH}$ and Titratable Acidity}

Results on hydrogen cyanide, $\mathrm{pH}$ and titratable acidity of samples in this study are presented in Table 3 . There were no significant differences in these parameters among samples $(\mathrm{p}>0.05)$. The $\mathrm{pH}$ of gari samples ranged from $5.3 \pm 0.08$ in Soy gari to $5.9 \pm 0.12$ in Control. Titratable acidity values ranged from $0.13 \pm 0.02$ in Control to $0.25 \pm 0.02$ in Soy gari. 
Table 3. Hydrogen Cyanide, $\mathrm{pH}$ and Titratable Acidity of Fortified Gari Samples.

\begin{tabular}{lllll}
\hline \multirow{2}{*}{ Parameter } & Samples & & & \\
\cline { 2 - 5 } & Control & Soy Gari & Melon Seed Gari & Moringa Seed Gari \\
\hline Hydrogen Cyanide $(\mathrm{mg} / \mathrm{Kg})$ & $6.73 \pm 0.05^{\mathrm{a}}$ & $6.29 \pm 0.04^{\mathrm{a}}$ & $6.51 \pm 0.04^{\mathrm{a}}$ & $6.63 \pm 0.02^{\mathrm{a}}$ \\
pH & $5.9 \pm 0.12^{\mathrm{a}}$ & $5.3 \pm 0.08^{\mathrm{a}}$ & $5.5 \pm 0.10^{\mathrm{a}}$ & $5.7 \pm 0.06^{\mathrm{a}}$ \\
Titratable Acidity & $0.13 \pm 0.02^{\mathrm{a}}$ & $0.25 \pm 0.02^{\mathrm{a}}$ & $0.21 \pm 0.04^{\mathrm{a}}$ & $0.19 \pm 0.01^{\mathrm{a}}$ \\
\hline
\end{tabular}

Mean \pm SD of triplicates. Values with the same superscript along each row are not significantly different

\subsection{Sensory Characteristics}

Enrichment did not result in significant differences in sensory properties of most samples $(p>0.05)$. The control sample scored best for colour (1.25), taste (1.80) and aroma
(1.55). Moringa seed gari scored poorest in all colour (3.45), taste (3.05), aroma (2.80) and overall acceptability (3.40). Melon seed gari performed best in overall acceptability (1.55).

Table 4. Sensory Characteristics of Fortified Gari Products.

\begin{tabular}{|c|c|c|c|c|}
\hline \multirow{2}{*}{ Sensory Characteristics } & \multicolumn{4}{|l|}{ Samples } \\
\hline & Control & Soy Gari & Melon Seed Gari & Moringa Seed Gari \\
\hline Colour & $1.25^{\mathrm{b}}$ & $1.80^{\mathrm{b}}$ & $1.30^{\mathrm{b}}$ & $3.45^{\mathrm{a}}$ \\
\hline Taste & $1.80^{\mathrm{b}}$ & $2.20^{\mathrm{b}}$ & $2.10^{\mathrm{b}}$ & $3.05^{\mathrm{a}}$ \\
\hline Aroma & $1.55^{\mathrm{c}}$ & $2.30^{\mathrm{ab}}$ & $1.95^{\mathrm{bc}}$ & $2.80^{\mathrm{a}}$ \\
\hline Overall Acceptability & $1.70^{\mathrm{b}}$ & $2.00^{\mathrm{b}}$ & $1.55^{\mathrm{b}}$ & $3.40^{\mathrm{a}}$ \\
\hline
\end{tabular}

Mean of triplicates. Values with the same superscript along each row are not significantly different

\section{Discussions}

Fortification of gari samples resulted in decreased moisture, fibre and carbohydrate contents; whereas, protein, fat and ash contents were increased. Similar observations have been made in gari samples fortified with sesame seed and African breadfruit respectively in previous studies $[6,17]$. All samples had moisture contents below the recommended $12 \%$ for gari [18]; an indication of good keeping quality. Protein contents were recorded in increasing order from control, Moringa seed gari, Melon seed gari and Soy gari. These observations could be reflective of the protein content of individual fortifying materials [9-11, 19]. Fat content of Melon seed gari in this study is comparable to $10.20 \%$ reported for fat content of gari fortified with 5\% sesame seed [6]. High fat content of gari fortified with these materials can be of relevance in situations where higher energy intake from gari is desirable. Fortification decreased fibre contents of all samples, except for Moringa seed gari. This is not unexpected as moringa seed is reported to have high crude fibre content [11] than other fortifying materials [19-20], and even cassava root [21]. Moringa seed gari had comparable ash content with the Control and Soy gari, whereas, Soy gari was slightly similar in ash content to Melon seed gari. Absence of substantial differences in ash contents between fortified and unfortified samples have been reported in previous studies on fortification of gari with soy beans and groundnut $[8,22]$, suggesting these materials may not differ significantly in their mineral contents. The decrease in carbohydrate contents of samples could have resulted from increase in other nutrients (protein, fat and ash) from fortifying food materials.

There were significant differences in pasting properties of samples in this study. Moringa seed gari performed better than other samples in peak viscosity and trough, but poorly in breakdown viscosity. It has been reported that, lower breakdown viscosity showed higher resistance to paste disintegration in response to heat; a desired characteristic of starch granules with lower peak viscosities [23]. In this case, other samples with lower breakdown viscosities performed better, with Soy gari likely to show the highest level of resistance. Gari processed from 100\% cassava (Control) had the highest final viscosity. This observation conforms to reports from previous works on fortification of gari with soymelon blends, cocoyam and fortification of cassava flour with sorghum, where $100 \%$ cassava products usually have the highest final viscosities [7, 23-24].

Final viscosity indicates the ability of starch granules to form paste after cooling and the instability of such paste which is commonly accompanied with high degree of breakdown [25]. Control sample had a higher tendency of becoming firmer with cooling, accompanied by increased resistance to enzymatic attack and lower digestibility $[7,26]$ than other samples. All samples in this study could form paste below boiling temperature as pasting temperature ranged from $72.35^{\circ} \mathrm{C}$ to $89.97^{\circ} \mathrm{C}$. Pasting properties of food materials vary significantly based on substitution levels [7, 23-24]. It is possible that, the $5 \%$ level of substitution adopted in this study contributed to the wide differences in pasting characteristics of sample in this study in comparison to previous studies.

Functional properties decreased significantly in fortified gari samples $(p<0.05)$. The lowering effect of enrichment on swelling index of fortified products can be attributed to reduced starch component in the enriched samples leading to lower capacity of the samples to absorb water [27]. Water holding capacity measures the extent to which macromolecules can entrap large amount of water without the possible incidence of exudation [23, 28]. Moringa seed gari 
(23.05 \pm 0.05$)$ competed well with the Control in water holding capacity $(p>0.05)$. Findings on the effect of substitution of cassava on functional properties of samples in this study are comparable with observations from previous works [7, 29].

The range of hydrogen cyanide obtained from samples in this study fell within acceptable ranges [15] and are even lower than those reported in a study on fortification of gari with sesame seed flour [6]. The $\mathrm{pH}$ values obtained from samples in this study were higher than the recommended range of 3.5 to 4.5 for good fermented products [23, 30]. Low $\mathrm{pH}$ is necessary for good keeping quality of any sample [29]. Enrichment also led to increase in Titratable acidity, but resulted in gari products with values below recommended upper limit of $1.0 \%$ [18]. Figures obtained from this study, especially for Soy gari and Melon seed gari are comparable to those previously reported for Soy gari [31].

Moringa seed gari scored significantly lower than others in all sensory parameters, except aroma where it was comparable with Soy gari. The poor rating for Moringa seed gari in colour can be attributed to the appearance of dark colour of the leafy particles from moringa seeds. Ordinarily, Moringa seed has a slightly bitter-sweet taste with no distinct flavour, while soybean is known for its repulsive odour. It is not surprising that samples containing these materials scored generally lower than others in sensory properties. Adequate processing techniques, especially for soybean have proven effective in improving the acceptability of the product. Gari processed from $100 \%$ cassava scored best in all parameters, except for overall acceptability, where Melon seed gari scored the best. These observations indicate some kind of influence on sensory properties of samples by individual characteristics of the fortifying agents.

\section{Conclusions}

Enrichment of cassava with soybean, melon seed and moringa seed flours at 5\% level can lead to significant improvements in nutritive values of the final gari products. The process influenced pasting properties and reduced functional properties of gari; inclusion of Moringa seed flour particularly resulted in gari sample that competed favourably with $100 \%$ cassava gari in pasting properties. All gari samples performed well in sensory properties, except, gari processed with moringa seed powder which can be improved with adequate processing. Fortification of this product can thus present a viable and sustainable means of tackling nutrient deficiencies, particularly protein energy malnutrition in populations.

\section{References}

[1] Sanni, L. O. (2005). Food Safety, Weights, Measures, and Consumption Patterns: The Case of Gari in Enugu and Benin Markets. Onne, Nigeria: International Institute of Tropical Agriculture.

[2] Fabiana F. De Moura, Mourad Moursi, Abdelrahman Lubowa,
Barbara Ha, Erick Boy, Babatunde Oguntona, Rasaki A. Sanusi, Busie Maziya-Dixon. (2015). Cassava Intake and Vitamin A Status among Women and Preschool Children in Akwa-Ibom, Nigeria. PLoS ONE 10 (6): e0129436.

[3] Yusuf A. Z., Zakir A., Shemau Z., Abdullahi M., Halima S. A., and SANI K. (2014). Visual defects among consumers of processed cassava (gari). Af rican Journal of Food Science. Vol 8 (1): 25-29.

[4] Olasore, A. H and Samuel, T. A. (2010). Gari Based Kwashiokorrigenic Diets Compromised some Renal Functions in Albino Rats. Asian Journal of Clinical Nutrition, 2: 215-220.

[5] Olaf Müller and Micheal Krawinkel. Ahmad H, Liaqat P, Paracha P, Qayyum A, Uppal MA. (2005). Malnutrition and health in developing countries. CMAJ. 2; 173 (3): 279-286.

[6] Oluwamukomi, M. O. (2015). Chemical and Sensory Properties of Gari Fortified with Sesame Seed Flour (Sesamum Indicum L.) FUTA Journal of Research in Sciences, 2015 (1): 123-131.

[7] Oluwamukomi, M. O., Jolayemi, O. S. (2012). Physicothermal and pasting properties of soy-melon-enriched "gari" semolina from cassava. Agric Eng Int: CIGR Journal, Vol. 14, No. 3, 105-116.

[8] Arisa, N. U., O. B. Omosaiye, A. O. Adelekan and A. AlabiMac Foy, (2011). Chemical and Sensory qualities of gari fortified with groundnut flour. Afri. J. Food Sci. Technol., 2 (5): 116-119.

[9] Besong, S. A., Ezekwe, M. O., Fosung, C. N. and Senwo, Z. N (2011). Evaluation of nutrient composition of African melon oilseed (Cucumeropsis mannii Naudin) for human nutrition International Journal of Nutrition and Metabolism Vol. 3 (8), pp. $103-108$.

[10] Lokuruka Mni. (2010). Soybean Nutritional Properties: The Good and The Bad About Soy Foods Consumption-A Review. African Journal of Food Agriculture, Nutrition and Development, 10 (4): 2439-2459.

[11] Aja, P. M., Ibiam, U. A., Uraku, A. J., Orji, O. U., Offor, C. E. and Nwali, B. U. (2013). Comparative Proximate and Mineral Composition of Moringa oleifera Leaf and Seed. Global Advanced Research Journal of Agricultural Science (ISSN: 2315-5094) Vol. 2 (5) pp. 137-141.

[12] Odunfa, S. A. (1998). Cassava to gari. Nigerian Journal of Science and Technology. 1: 186-189.

[13] AOAC (2000). Association of Official Analytical Chemists. Official Methods of Analysis, 17th Edition, Washington D. C.

[14] Beuchat, (1977). Functional and electrphorectic characteristics of succinylated peanut flour proteins. J. Agric. Food Chem., 25: 258-261.

[15] Ukpabi, U. J. and C. Ndimele, (1990). Evaluation of the quality of garri produced in Imo State. Nig. Food J., 8: 105-109.

[16] Cook, R. D. and E. N. Maduagwu, (1978). The effect of simple processing on the cyanide content of cassava chips. J. Food Technol., 13: 299-306.

[17] Onasoga, M. O., Ayodele, D. O., Oyeyipo, O O. (2014). Chemical Changes during the Fortification of Cassava Meal (Gari) with African breadfruit (Treculia africana) Residue. J. Appl. Sci. Environ. Manage, 18 (3): 506-512. 
[18] CODEX STAN 151, (1989). Rev. 1-1995. Codex Alimentarius Commission Standard for gari. Pp 1-6.

[19] Egbebi A. O. (2014). Comparative studies on the three different species melon seed; (Citrulus vulgaries, Cucumeropsis manni and Leganaria siceraria). Sky Journal of Food Science Vol. 3 (1), pp. 001-004.

[20] Teresa Banaszkiewicz (2011). Nutritional Value of Soybean Meal, Soybean and Nutrition, Prof. Hany El-Shemy (Ed.), ISBN: 978-953-307-536-5, InTech, Available from: http://www.intechopen.com/books/soybeanandnutrition/nutritional-value-of-soybean-meal.

[21] Montagnac, J. A., Davis, C. R. and Tanumihardjo, S. A. (2009). Nutritional Value of Cassava for Use as a Staple Food and Recent Advances for Improvement. Comprehensive Reviews in Food Science and Food Safety, 8: 181-194.

[22] Adelodun Lawrence Kolapo and Morenike Olayinka Sanni (2009). A comparative evaluation of the macronutrient and micronutrient profiles of soybean-fortified gari and tapioca. Food and Nutrition Bulletin, vol. 30, no. 1, 90-94.

[23] Olatunde, S. T, Olatunde, S. J and Ade-Omowaye, B. I. O. (2013). Production and evaluation of gari produced from cassava (Manihot esculenta) substituted with cocoyam (Colocasia esculenta) PAK. J. FOOD SCI., 23 (3), 124-132.

[24] Osungbaro, T. O; Jimoh, D, and Osundeyi, E. (2010). Functional and pasting properties of composite CassavaSorgum flour meals. Agric. Biol. J. N. Am., 2010, 1 (4): 715720 .

[25] Ikegwu, O. J, Okechukwu, P. E andEkumankana, E. O. (2010).
Physico-Chemical and Pasting Characteristics of Flour and Starch from Achi Brachystegia eurycoma Seed. Journal of Food Technology. Vol. 8 (2): 58-66.

[26] Shittu, T. A., O. O. Lasekan, L. O. Sanni, and M. O. Oladosu. (2001). The effect of drying methods on the functional and sensory characteristics of pupuru-a fermented cassava product. ASSET-An International Journal of Agricultural Sciences, Science, Enviroment and Technology, 1 (2): 9-16.

[27] Oluwamukomi, M. O., I. A. Adeyemi, and I. B. Oluwalana (2005). Effects of soybean supplementation on the physicochemical and sensory properties of gari. Applied Tropical Agriculture, 10 (Special issue): 44-49.

[28] Chen, M. J. and Lin, C. W. (2002). Factors affecting the water holding capacity of fibrinogen/plasma protein gels optimized by response surface methodology. Journal of Food Science 67 (7): 2579-2582

[29] Bankole, Y. O., Tanimola, O. A., Odunukan, R. O., Samuel, Samuel, D. O. (2013). An Assessment of the Functional Properties, Proximate Composition, Sensory Evaluation and Rheological Value of Gari Fortified with Bambara Groundnut Flour (Voandzeia Subterranean Thouars). Academic Journal of Interdisciplinary Studies, Vol 2 No 10, 165-173.

[30] Bainbridge Z, Tomlins K, Wellings K, Westby A (1996). Methods for Assessing Quality Institute, Ghatham, UK, pp. 22-23.

[31] Ugwu, F. M. and Odo, M. O. (2008). Effect of Cassava Variety on the Quality and Shelf Stability of Soy-Garri. Pakistan Journal of Nutrition 7 (2): 381-384. 